\title{
Identification Method of Task Community Based on Bayesian Belief Network
}

\author{
Xuezhi $\mathrm{Lv}^{1,2, *}$ and Changjiang $\mathrm{Liu}^{2}$ \\ ${ }^{1}$ Education and Research Department, National Defense University, Beijing, China \\ ${ }^{2}$ Education and Research Department, The $9^{\text {th }}$ Training Base of Army, Zhangjiakou, China \\ ${ }^{*}$ Corresponding author
}

\begin{abstract}
With the increaseing of the combat capability of the weapon platform, the striking range of the weapon platform is expanding, and it is necessary to classify the weapon platform according to the target that the weapon platform may hit. It can distinguish the task community, enhancing the cognition and supporting combat decision. Therefore, this paper discusses the issue of task community identification. First, the concept of the task community was introduced. Then, it explores the ideas and methods framework of task community identification. Then, we discuss the method of target attempt evaluation based on Bayesian network, and analyze the structure of Bayesian network model and how to determine the conditional probability table. Finally, a simulation example is given to demonstrate the feasibility and effectiveness of the method.
\end{abstract}

Keywords-task community; bayesian belief network; conditional probability table; target grouping

\section{INTRODUCTION}

As the range and precision of modern weapons continue to increase, the weapons platforms at different places can strike the same target. In order to enhance awareness of the situation and assist combat decision, it is needed to identify and distinguish enemy target based on which target they may strike. This problem can be referred to as task community identification problem. This issue is a problem of target grouping in the field of situational awareness ${ }^{[1]}$. The target group includes the target object group, spatial groups, task group from the low level to the high level. The task community can regard as a task group, and task community identification can be regarded as an identification of task group problem. The task group refers to a group of multiple tactically related spatial groups, and each task group has a tactical objective, which is achieved through the coordinated operation of multiple spatial groups.

Many scholars of have studied on the problem of target grouping. Svenson pointed out that Clustering/Grouping of vehicle/original object is one of the important steps in force aggregation and believes that this technology helps Raise the commander's understanding of the battlefield behavior ${ }^{[2]}$. Schubertet et al. gave a template selection method based on the D-S theory, which resulted in a greater improvement in the accuracy of grouping ${ }^{[3]}$. Cantwell et al. gave a neural network grouping method based on template technology ${ }^{[4]}$. Yu pointed out that due to the inability to give initial $\mathrm{k}$ values in advance, target clustering cannot use the usual clustering algorithm K- means ${ }^{[5]}$. Although domestic researches started latterly, but it achieved a lot of results. Long et al. proposed a space target grouping method based on kernel function and CNM algorithm ${ }^{[6]}$. Zhao et al. proposed a battlefield target grouping method of situation recognition system based on Agent [7]. $\mathrm{Li}$ et al. established OG-Brusselator model for battlefield object grouping, and modified MEC algorithm ${ }^{[8]}$.Wang et al. grouped battlefield object according to their levels with high dimension similarity function ${ }^{[9]}$. Duane al. proposed a method based on binary tree multi-class support vector machine (SVM) for target grouping ${ }^{[10]}$. Wang et al. proposed a support vector clustering algorithm based on data field, aiming at train sample vector instability with support vector clustering algorithm [11]. Zhang Julian et al. proposed a method for grouping ground maneuver targets based on an improved K-means algorithm ${ }^{[12]}$. From this, it can be seen that most domestic and overseas scholars regard the target grouping problem as a clustering problem, and various clustering methods are used to solve the problem. However, only studied the problem of grouping of spatial groups, and the problems of Functional groups and interacting group are less researched. This article will discuss the problem of task community.

\section{TASK COMMUNITY}

Target grouping is grouping these target objects step by step according to a certain relationship. The target grouping level can be divided into five levels, as shown in Figure I.

(1) Object groups individual threat units, namely individual entities in the battlefield;

(2) Spatial groups: groups in same space that are divided according to certain classification rules. In the same group, the object units have the same attributes, similar locations, and similar behavior;

(3) Functional groups: spatial groups that perform similar functions, still belong to the spatial groups in a certain sense. From many existing literature, Functional groups is thought as belonging to the spatial groups.

(4) Interaction group: Multiple tactically related spatial groups form an interaction group, and each interaction group has a tactical goal (as an attack or defend against of the same target, through multiple spatial groups working together. Essentially based on spatial groups grouping;

(5) Own/ Enemy/ Neutral Groups: divides all interacting 
groups into 3 groups by enemy, friendly, neutral, forming three camps of the battlefield.

In addition, in order to simplify the analysis process, target groups can also be divided into target group, spatial groups and task group. According to the definition of functional groups, functional groups can be classified as spatial groups. The interaction group has the same task, so it is grouped into the task group/task community. In a certain sense, the enemy/friendly/neutral group has the same overall mission, so it is also possible to apply enemy/ friendly/ neutral groupware grouped into the top of task group/ task communities. The task community refers to group of the same task. It can be seen from the Figure I that the recognition of the task community needs to take into account factors, such as target object attributes, combat operations, spatial groups, tasks and purpose. In a complex battlefield environment, each side formulates a battle plan based on operational intent, allocates tasks for each task group, and implements operational intent through task groups performing combat tasks. Distinguishing the enemy mission community can be an effective means to judge enemy intentions.

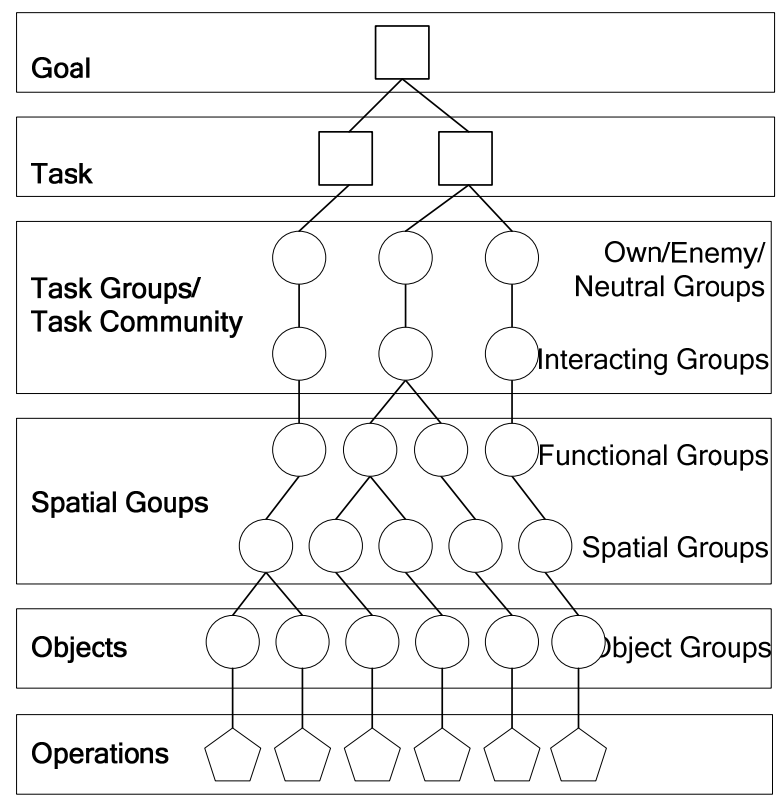

FIGURE I. HIERARCHY OF GROUPS

\section{CONCEPT AND METHOD FRAMEWORK OF TASK COMMUNITY RECOGNITION}

The task community refers to the group of same task that is used to identify the deployment of to enemy forces performing the same task. Taking the mission of enemy attack on our target as an example, we did not know which target our enemy's weapons platform or weapons attempted to attack before the enemy launched a strike. Before the enemy's weapon platform or weapon attacks our target, in order to increase the success probability of the strike, they may also take some tactical actions to carry out attacks, for example feign (false) attack, and increase the difficulty in judging the enemy's attack target. Before attacking our target, the attack attempt (attack probability) of enemy's weapon platform or weapon to our target is different, and changes over time. Therefore, our judgment on whether the enemy's weapon platform and the formation of the weapon belong to same task community needs to use attack attempt of an enemy weapon platform or weapon to classify our target.

Suppose our target set is $N$, the enemy target set is $M$, and the enemy group set is $L$. At time of $t$, the attack attempt of enemy target $m(m \in M)$ to our target $n \in(n \in N)$ is $T_{m n}{ }_{m n}\left(T_{m n} \in\{\mathrm{I}\right.$, II, III, IV, V\}). If the maximum attack attempt of enemy target to our target is the same, the enemy target and its subordinate units can be classified into the same task group. At the moment of $t$, enemy spatial groups l can be classified into task group $C_{n}^{t}$ $\left(\left\{C_{n}^{t} \mid \max _{m \in M} T_{m n}{ }_{m n}=\max _{m^{\prime} \in M} T_{m^{\prime} n}, \quad m \neq m^{\prime}, \quad m \in L_{l}, m^{\prime} \in L_{l}^{\prime}, \quad n \in N\right.\right.$, $L_{l} \cup L_{l}, C_{n}^{t} \subseteq L^{\})}$.

As shown in Figure II, the maximum attack attempt of targets 1 and targets 2 to our target 1 is same level V, and then the group corresponding to target 1 and target 2 can be classified into the task community $\mathrm{C} 1$. Attack attempt of targets 3 and targets5for our target 2 are most maximum, and are At level IV, group 1 and group 2 corresponding to targets 3 and targets 5 can be classified into task community C2.The maximum attack attempts of target 4 and Target 6 towards our target 3 are all Level III, the group 1 and the group 2 corresponding to the target 4 and target 6are classified into the task community C3. The maximum attack attempts of target 7 and Target 9 towards our target 4are all at Level III, then the grouping 3 and grouping 4 corresponding to target 7 and target 9 can be classified into task community C4.
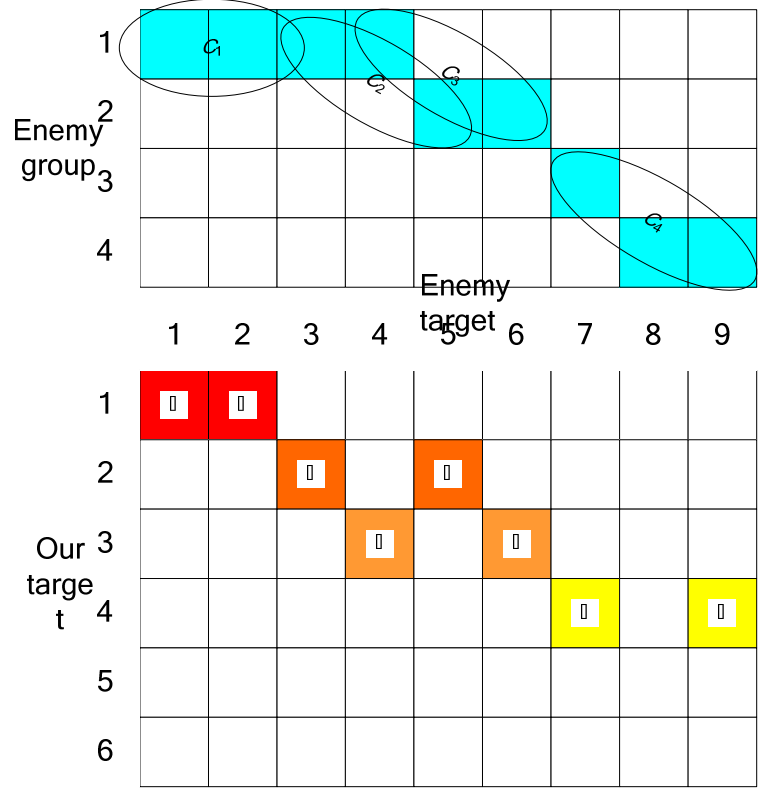

FIGURE II. DIAGRAM OF TASK GROUP CLASSIFICATION

Figure III is the framework of task community recognition. It can be seen as time goes by, it is required that continuous calculation attack attempt of each enemy target towards our target, and then classify the enemy spatial groups whose attack tempt are same into same task community according to the task community identification formula. 


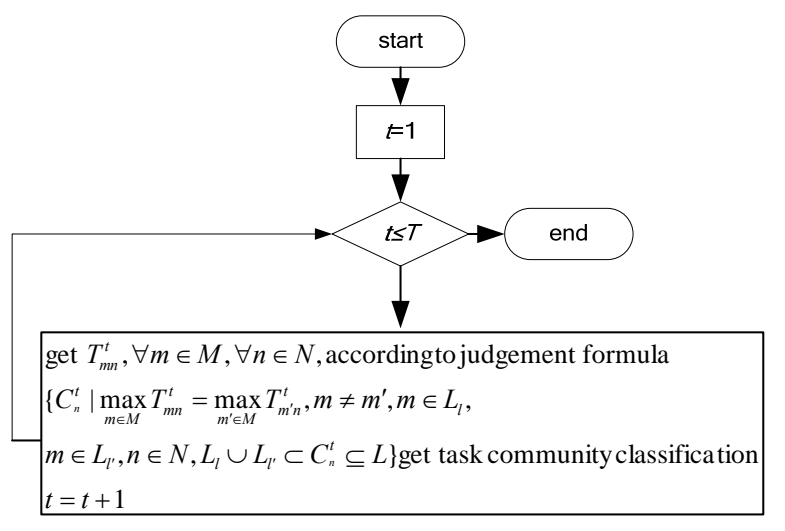

FIGURE III. FRAMEWORK OF TASK COMMUNITY CLASSIFICATION

\section{TARget AtTEMPt EVAluation BAsEd on BAyEsian NETWORK}

At present, methods for attempt assessment are most commonly found in methods of threat estimation, and most of them adopt the methods of multi-attribute decisions, neural networks, template matching, fuzzy math and simple influence factor weighting methods. Although, these methods all have some utility and pertinence, but they also has some disadvantages. For example, a neural network can learn through samples, but it requires a lot of real and reliable samples. Multi-attribute decision-making depends on the knowledge of experts, is subjective and uncertain, and cannot be learned. Therefore, this article adopts Bayesian networks (Bayesian networks, BN) to establish enemies target attempt assessment model. This method can be well combined with expert knowledge and reasoning based on uncertain information, solves critical problem of enemy target attempt estimation, and it will have the following advantages:

- The Bayesian network conforms to the human mindset, uses a graphical network model to express knowledge in the military field, and at the same time, through a semantic, logic reasoning to solve the problem of uncertainty.

- The Bayesian network organically combines knowledge and experience (a priori information) of the domain expert and situational information (sample data), not only did serve the adverse effect of subjective factors, but reduced the noise in the sample data.

- The Bayesian network is organically integrated with qualitative, quantitative analysis. It can infer the target's attempt based on partial information in case situation information is missing, and its reasoning based on probabilistic model and probability calculation ensures that the inferential result is reliable.

- The Bayesian network model is able to describe the continuous and cumulative change of the target attempt. Many methods that have not memory function cannot achieve this time consistency feature..

\section{A. Bayesian Network}

Bayesian networks, also known as confidence networks, probability networks, trust networks, or causal networks, are mainly composed of two parts of the network structure and conditional probability tables.

(1) The network structure is a DAG (Directed Acyclic Graph) with $\mathrm{N}$ nodes. The nodes in the graph are the abstract representations of the problems. The directed edges represent the relationships between the connected nodes, which is usually a causal relationship. The directed graph implies the assumption of conditional independence. The Bayesian network specifies that every node $V_{i}$ in the graphic independent of a subset that is made up of descendant nodes of the parent of $V_{i}$ except $V_{i}$. If A is used to represent subset of any descendant nodes except $V_{i}, P_{\mathrm{a}}\left(V_{i}\right)$ is used to represent the parent node of $V_{i}$

$$
P\left(V_{i} \mid A\left(V_{i}\right), P_{a}\left(V_{i}\right)\right)=P\left(V_{i} \mid P_{a}\left(V_{i}\right)\right)
$$

(2) Conditional Probability Table (CPT) is a set of local probability distributions that reflect the correlation between variables, that is, a probability parameter, which can be $P\left(V_{i} \mid\right.$ $P_{a}\left(V_{i}\right)$ ). It expresses the correlation between the node and its parent node, namely the conditional probability. The root node has no conditional probability, which is the prior probability.

When the Bayesian network structure and its conditional probability table are known, the joint probability density of all nodes (variable) in the network can be expressed, and probability information of some nodes can be calculated basing on prior probability information or the value of some node. Applying conditional independence to chain rules, we can get:

$$
P\left(V_{1}, V_{2}, \Lambda, V_{n}\right)=\prod_{i=1}^{n} P\left(V_{i} \mid P_{a}\left(V_{i}\right)\right)
$$

It can be seen that the Bayesian network can express the joint probability distribution of variables and greatly simplify the solution of the joint probability of variables.

\section{B. Bayesian Network Structure Model}

The attempt of targets can be reflected by multiple factors, including the type of target, path shortcut, distance, speed, altitude, tactical maneuver, electronic interference, value and vulnerability of our target. The interaction and correlation among these factors, jointly reflect the degree of attack attempt to our goal (See Figure IV). 


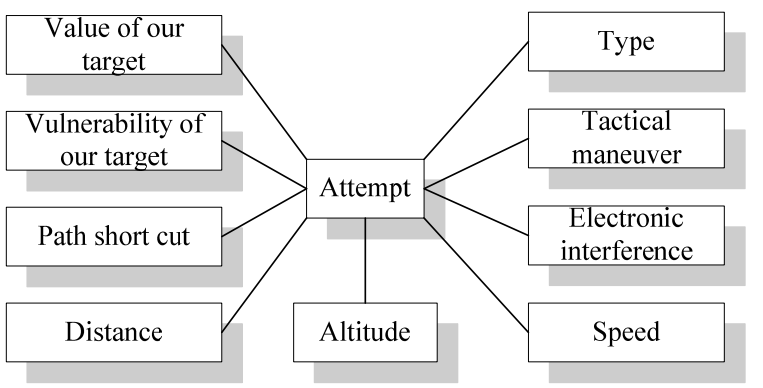

FIGURE IV. BAYESIAN NETWORK STRUCTURE

\section{Bayesian Network Node Properties}

Based on domain expert experience and knowledge, air attack tactics and related literature, the description the node attributes of the Bayesian network, as shown in the Table I.

\section{TABLE I. PROPERTY OF NODE}

\begin{tabular}{|c|c|c|}
\hline node & Types of & Description \\
\hline Attempt(TE) & Discrete & $\begin{array}{lll}\text { (V, IV, III, II, I } & & \\
\text { ffighter(fighter } \quad \text { Bomber } \quad \text { Striker, }\end{array}$ \\
\hline Target Type(TY) & Discrete & $\begin{array}{l}\text { Missle (Air-to-Earth Missile, Cruise } \\
\text { Missile, Anti-radiation Missile)\} }\end{array}$ \\
\hline $\begin{array}{l}\text { Target Route } \\
\text { Shortcut(z) }\end{array}$ & continuous & $\begin{array}{l}\text { \{Short }(\mathrm{z} \leqslant 1.5 \mathrm{~km}),(1.5 \mathrm{~km}<\mathrm{z} \leqslant \\
\text { 3km),Length }(\mathrm{z}>3 \mathrm{~km})\}\end{array}$ \\
\hline Target distance(d) & continuous & $\begin{array}{l}\{\text { Near }(\mathrm{d} \leqslant 30 \mathrm{~km}) \text {, middle }(30 \mathrm{~km}<\mathrm{d} \\
\leqslant 90 \mathrm{~km}), \operatorname{far}(\mathrm{d}>90 \mathrm{~km})\}\end{array}$ \\
\hline Target height(a) & continuous & $\begin{array}{l}\{\text { Low }(\mathrm{a} \leqslant 4 \mathrm{~km}), \text { middle }(4 \mathrm{~km}<\mathrm{a} \leqslant \\
10 \mathrm{~km}), \operatorname{high}(\mathrm{a}>10 \mathrm{~km})\}\end{array}$ \\
\hline Target speed(s) & continuous & $\begin{array}{l}\{\text { supersonic }(\mathrm{s} \geqslant 340 \mathrm{~m} / \mathrm{s}), \\
\operatorname{Speed}(200 \mathrm{~m} / \mathrm{s}<\mathrm{s} \leqslant 340 \mathrm{~m} / \mathrm{s}), \text { low }- \\
\text { speed }(\mathrm{s}<200 \mathrm{~m} / \mathrm{s})\}\end{array}$ \\
\hline $\begin{array}{l}\text { Target } \\
\text { Maneuver(m) }\end{array}$ & Discrete & $\{$ has maneuver, no maneuver $\}$ \\
\hline $\begin{array}{l}\text { Target Electronic } \\
\text { Interference(j) }\end{array}$ & Discrete & $\begin{array}{l}\{\text { has interference, } \\
\text { interference }\}\end{array}$ \\
\hline $\begin{array}{l}\text { Our } \\
\text { value(v) }\end{array}$ & Discrete & \{high, middle , low $\}$ \\
\hline $\begin{array}{l}\text { Our target } \\
\text { vulnerability(f) }\end{array}$ & Discrete & \{high, middle, low $\}$ \\
\hline
\end{tabular}

D. Conditional Probability Table of Bayesian Network Node

To determine the conditional probability table of a Bayesian network node, usually two methods are used: one is the expert method, and the conditional probability table is directly obtained using domain expert knowledge. The other is parametric learning, including EM or improved algorithms such as (See Table II).
TABLE II. CONDITIONAL PROBABILITY TABLES OF ATTEMPTS EVALUATION

\begin{tabular}{|c|c|c|c|c|c|c|}
\hline \multirow{2}{*}{$\begin{array}{l}\text { Probability } \\
\text { value }\end{array}$} & \multirow{2}{*}{ variable } & \multicolumn{5}{|l|}{ TE } \\
\hline & & $\mathbf{V}$ & IV & III & II & $\mathbf{I}$ \\
\hline \multirow[t]{2}{*}{$\mathrm{P}(\mathrm{TY} \mid \mathrm{TE})$} & fighter & 0.40 & 0.49 & 0.60 & 0.70 & 0.80 \\
\hline & missile & 0.60 & 0.51 & 0.40 & 0.30 & 0.20 \\
\hline \multirow[t]{3}{*}{$P(z \mid T E)$} & short & 0.86 & 0.63 & 0.31 & 0.12 & 0.04 \\
\hline & in & 0.12 & 0.21 & 0.49 & 0.16 & 0.17 \\
\hline & long & 0.02 & 0.16 & 0.20 & 0.72 & 0.79 \\
\hline \multirow[t]{3}{*}{$P(\mathrm{~d} \mid \mathrm{TE})$} & near & 0.85 & 0.64 & 0.3 & 0.11 & 0.03 \\
\hline & in & 0.14 & 0.20 & 0.50 & 0.15 & 0.17 \\
\hline & far & 0.01 & 0.16 & 0.20 & 0.74 & 0.80 \\
\hline \multirow{3}{*}{$P(\mathrm{a} \mid \mathrm{TE})$} & low & 0.7 & 0.6 & 0.3 & 0.3 & 0.3 \\
\hline & in & 0.1 & 0.2 & 0.5 & 0.2 & 0.1 \\
\hline & high & 0.2 & 0.2 & 0.2 & 0.5 & 0.6 \\
\hline \multirow[t]{3}{*}{$\mathrm{P}(\mathrm{s} \mid \mathrm{TE})$} & Supersonic & 0.84 & 0.60 & 0.25 & 0.13 & 0.01 \\
\hline & high speed & 0.14 & 0.29 & 0.50 & 0.25 & 0.16 \\
\hline & $\begin{array}{l}\text { Medium and } \\
\text { low speed }\end{array}$ & 0.02 & 0.11 & 0.25 & 0.62 & 0.83 \\
\hline \multirow[t]{2}{*}{$\mathrm{P}(\mathrm{m} \mid \mathrm{TE})$} & Mobile & 0.95 & 0.80 & 0.50 & 0.30 & 0.15 \\
\hline & No motor & 0.05 & 0.20 & 0.50 & 0.70 & 0.85 \\
\hline \multirow[t]{2}{*}{$P(\mathrm{j} \mid \mathrm{TE})$} & $\begin{array}{l}\text { There is } \\
\text { interference }\end{array}$ & 0.80 & 0.70 & 0.45 & 0.30 & 0.25 \\
\hline & $\begin{array}{l}\text { No } \\
\text { interference }\end{array}$ & 0.20 & 0.30 & 0.55 & 0.70 & 0.75 \\
\hline \multirow[t]{3}{*}{$P(v \mid T E)$} & high & 0.85 & 0.64 & 0.3 & 0.11 & 0.03 \\
\hline & in & 0.14 & 0.20 & 0.50 & 0.15 & 0.17 \\
\hline & low & 0.01 & 0.16 & 0.20 & 0.74 & 0.80 \\
\hline \multirow[t]{3}{*}{$P(f \mid T E)$} & high & 0.85 & 0.64 & 0.3 & 0.11 & 0.03 \\
\hline & in & 0.14 & 0.20 & 0.50 & 0.15 & 0.17 \\
\hline & low & 0.01 & 0.16 & 0.20 & 0.74 & 0.80 \\
\hline
\end{tabular}

\section{TARget AtTEMPt EVAluation Based on BAyEsian} NETWORK

Take the joint operation as the operational background, and deal with the battlefield situation. Deployment and enemy target location are shown in Figure V, Our target information is shown in Table III.

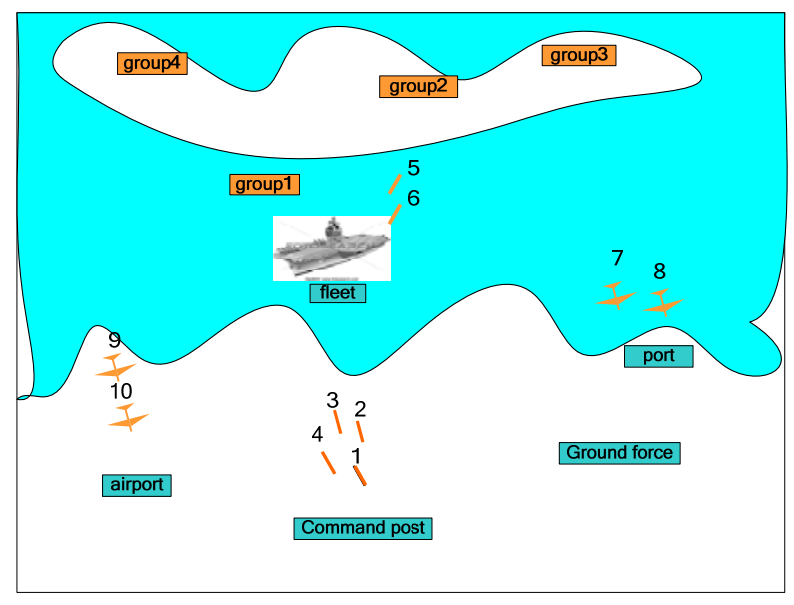

FIGURE V. DIAGRAM OF DEPLOYMENT AND ENEMY OBJECTS 
TABLE III. OUR TARGET INFORMATION

\begin{tabular}{|c|c|c|c|c|c|c|}
\hline \multirow{2}{*}{\multicolumn{2}{|c|}{ No. name }} & \multirow[b]{2}{*}{ value } & \multicolumn{3}{|c|}{ vulnerability } & \multirow{2}{*}{$\begin{array}{l}\text { Bombardment } \\
\text { machine }\end{array}$} \\
\hline & & & $\begin{array}{l}\text { cruise } \\
\text { missile }\end{array}$ & Ground- & fighter & \\
\hline 1 & $\begin{array}{l}\text { command } \\
\text { post }\end{array}$ & high & in & high & in & low \\
\hline 2 & fleet & in & in & in & in & in \\
\hline 3 & port & in & high & high & low & in \\
\hline 4 & airport & in & high & high & high & in \\
\hline 5 & $\begin{array}{l}\text { Ground } \\
\text { forces }\end{array}$ & low & in & high & low & in \\
\hline
\end{tabular}

The enemy aircraft carrier formation, the airbase, and the missile base use various types of missiles and fighter to attack our targets ( command post, fleet, port, airport, ground force), assuming the number of targets detected at the time of $t$ is 10 , and the target information is shown in the Table IV.

TABLE IV. INFORMATION OF INCOMING TARGETS

\begin{tabular}{|c|c|c|c|c|c|c|}
\hline $\begin{array}{l}\text { Target } \\
\text { lot } \\
\text { number }\end{array}$ & $\begin{array}{l}\text { Target } \\
\text { type }\end{array}$ & $\begin{array}{l}\text { Height } \\
/ \mathrm{m}\end{array}$ & & Maneuver & interference & $\begin{array}{l}\text { Spatial } \\
\text { groups }\end{array}$ \\
\hline 1 & $\begin{array}{l}\text { cruise } \\
\text { missile }\end{array}$ & 150 & 310 & no & no & 1 \\
\hline 2 & $\begin{array}{l}\text { cruise } \\
\text { missile }\end{array}$ & 160 & 350 & no & no & 1 \\
\hline 3 & $\begin{array}{l}\text { cruise } \\
\text { missile }\end{array}$ & 180 & 310 & no & no & 1 \\
\hline 4 & $\begin{array}{l}\text { cruise } \\
\text { missile }\end{array}$ & 190 & 340 & no & no & 1 \\
\hline 5 & $\begin{array}{l}\text { Ground- } \\
\text { to- } \\
\text { ground } \\
\text { missiles }\end{array}$ & 3300 & 420 & yes & yes & 2 \\
\hline 6 & $\begin{array}{l}\text { Ground- } \\
\text { to- } \\
\text { ground } \\
\text { missiles }\end{array}$ & 3200 & 430 & yes & yes & 2 \\
\hline 7 & fighter & 2500 & 310 & yes & yes & 3 \\
\hline 8 & fighter & 2600 & 300 & yes & yes & 3 \\
\hline 9 & Bomber & 2100 & 320 & yes & yes & 4 \\
\hline 10 & Bomber & 2400 & 330 & yes & yes & 4 \\
\hline
\end{tabular}

According to the Bayesian network model proposed in this paper, the Bayesian network model is established using Netica software and inference is performed. Taking the inference of attack attempt of target 1 to the command post as an example, the figure 6 gives the input conditions and results. The enemy target's attack attempt to our target is shown in the Table V.

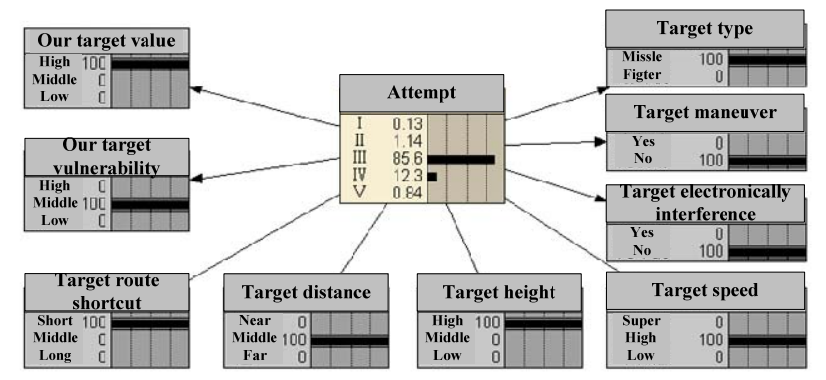

FIGURE VI. DIAGRAM OF BAYESIAN NETWORK INFERRING
TABLE V. ATTEMPT LEVEL OF TARGET TO OUR OBJECTS

\begin{tabular}{|c|c|c|c|c|c|}
\hline \multirow{2}{*}{$\begin{array}{l}\text { Target } \\
\text { lot } \\
\text { number }\end{array}$} & \multicolumn{5}{|l|}{ Our goal } \\
\hline & $\begin{array}{l}\text { command } \\
\text { post }\end{array}$ & fleet & port & airport & $\begin{array}{l}\text { Ground } \\
\text { forces }\end{array}$ \\
\hline 1 & III & I & I & II & II \\
\hline 2 & III & I & I & II & II \\
\hline 3 & III & I & I & II & II \\
\hline 4 & III & I & I & II & II \\
\hline 5 & I & III & I & I & I \\
\hline 6 & I & III & I & I & I \\
\hline 7 & I & II & III & I & II \\
\hline 8 & I & II & III & I & II \\
\hline 9 & II & II & I & III & I \\
\hline 10 & II & II & I & III & I \\
\hline
\end{tabular}

According to the above table and the task community identification method in 2, enemy formations can be classified, the specific content is shown in the Table VI. It can be seen from the table that the enemy formations are relatively independent, and each formation is an independent task community. Note that this is only a division of the task community at $t$. As time goes on, attack attempt of the enemy's target will change, and the division of the task community will change accordingly. The division of the task community at time $t$ is situation recognition of the moment $t$.

\section{TABLE VI. TASK COMMUNITY IDENTIFICATION}

\begin{tabular}{llllll}
\hline \multirow{2}{*}{$\begin{array}{l}\text { Enemy } \\
\text { formation }\end{array}$} & \multicolumn{2}{l}{ Our target } & & & \\
\cline { 2 - 5 } & $\begin{array}{l}\text { command } \\
\text { post }\end{array}$ & fleet & port & airport & $\begin{array}{l}\text { ground } \\
\text { forces }\end{array}$ \\
\hline 1 & $\sqrt{ }$ & & & & \\
2 & & $\sqrt{ }$ & & \\
3 & & & $\sqrt{ }$ & \\
4 & & & & $\sqrt{ }$ & \\
\hline
\end{tabular}

\section{REFERENCES}

[1] D. L. Hall, J. Llinas, “An introduction to multisensor data fusion,” Proceedings of the IEEE, 1997, 85(1), pp. 6-23, DOI: 10.1109/5.554205.

[2] [ ]P. Svenson, "Capabilities-based force aggregation using random sets," 2005 8th International Conference on Information Fusion. Vol. 2. IEEE, 2005, DOI: 10.1109/ICIF.2005.1591950.

[3] S. Johan, "Reliable force aggregation using a refined evidence specification from dempster-shafer clustering, " arXiv preprint cs/0305030 (2003).

[4] J. Cantwell, J. Schuben, T. Walter, "Conflict-based force aggregation." arXiv preprint cs/0305029 (2003).

[5] Yu, B., Giampapa, J., Owens, S., \& Sycara, K,” An evidential Model of multisensory decision fusion for force aggregation and classification," 2005 8th International Conference on Information Fusion, 2005, DOI: 10.1109/ICIF.2005.1591964

[6] Z. Long, Z. Zhang, "Research on methodology of target-grouping in force aggregation,” Computer Engineering and Applications, vol. 47, 2011, pp. 225-230, DOI: 10.3778/j.issn.1002-8331.2011.20.063.

[7] P. Zhao, T. Chang, W. Wei, "Battlefield Target Grouping Method Based on Multi-Agent,” Computer Engineering, vol. 37, 2011, pp. 152-155, DOI: 10.3969/j.issn.1000-3428.2011.21.052.

[8] Y. Li, S. Lao, G. Liu, "Maximum entropy object grouping algorithm based on dissipative structure theory," Systems Engineering Theory and Practice, vol. 32, 2012, pp. 2816-2824. 
[9] X. Wang, S. Yang, H. Lin, "Target clustering technology in sea battlefiel," Ship Electronic Engineering, vol. 33, 2013, pp. 25-28, DOI : 10.3969 / j .issn1672 - 9722.2013.11.009.

[10] T. Duan, D. Zhang, "Application of Multiclass SVM Based on Binary Tree in Target Grouping,” Radio Engineering, vol. 45, 2015, pp. 88-91, DOI:10.3969/j.issn.1003-3106.2015.06.24

[11] X. Wang, D. Li, A. Yong, "Improved Algorithm of Target Grouping Based on Data Field,” Firepower and Command Control, vol. 40, 2015, pp. $40-43$.

[12] X. Zhang, H. Zhang, X. Qi, W. Wang, Z. Wang, C Yin, "A clustering method of land battlefield maneuvering targets based on improved Kmeans algorithm,” Information Technology, vol. 40, 2016, pp. 40-43. DOI: 10.13274/j.cnki.hdzj.2016.03.032. 